\title{
A movable technological simulation system for kinematic analysis to provide immediate accurate feedback and predict javelin throw distance
}

\author{
Essam Eldin HASSAN \\ Department of Curriculums and Instruction, Faculty of Physical Education, Assiut University, Egypt. \\ Address Correspomdence to E. E. Hassan, essam_shaban71@yahoo.com
}

\begin{abstract}
The use of information technology (IT) and highly sophisticated devices in learning and evaluating training process is very common in today's sport sciences. The research aimed is a Trying to identify using of the biomechanical simulation system to evaluate physical variables in javelin throw. A new movable biomechanical simulation system to expect the javelin throwing distance and evaluate physical variables was developed, which consisted of a $800 \mathrm{~g}$ sledge to be accelerated along a rope. The release angle can be adjusted within the range of $26-40$ degrees. The takeoff height can be likewise adapted to the individual conditions of the athlete. By a laser-steered measure (LAVEG) the velocity of the throw carriage can be determined. 20 sport students were selected. The research proves that only 10 seconds are needed to show the expected distance. This research also recommends using this new movable technological biomechanical simulation system in learning and evaluating training processes.
\end{abstract}

Keywords: Biomechanics, javelin throw, simulation system.

\section{INTRODUCTION}

The javelin throw is one of the four throwing events in the Track and Field. It is a technically difficult discipline. Due to the large loads, especially in the shoulder and back area, In addition to a technically challenging discipline that requires high coordination ability and tremendous speed strength. In the javelin throw, the velocity at which the performer releases the implement is by far the most important factor. For an $80 \mathrm{~m}$ throw, the release velocity will be approximately $30 \mathrm{~m} \bullet \mathrm{s}-1$. For some elite athletes over $70 \%$ of this velocity is developed in the $50 \mathrm{~ms}$ immediately before the javelin release (16).

The javelin throw, can be said to be acyclic movement exercises performed at maximum velocity. Because of its contribution to release velocity, which is the key to achieving maximum throwing distance, speed is the essential prerequisite for success in these events. According to the laws of physics, release velocity has the greatest influence on distance attained in any throwing event. This is both a guiding and target parameter. Therefore, release velocity should always be maximized while the values of the other factors should be optimal. Achieving high release velocity values in any throwing event requires great accelerations and velocities of the body's kinetic chain.

The throwing phase in the javelin is main acceleration phase of the technical principle to the level to be attained power and release velocity with optimum angle (4) and (13). The basic acceleration stage starts from planting front leg position till the release of the javelin as Tutjowitsch (25) indicate and as it shows in Figure 1 according to the Joch (13).

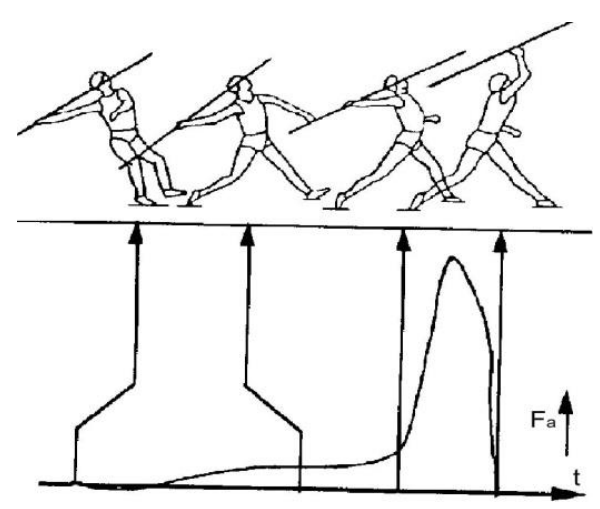

Figure 1. The acceleration phase in the javelin throw. 
To summarize, all these aspects of the acceleration curve demonstrate the connection between good technique and a speed-strength ability that is specific to the javelin throw.

Bauersfeld \& Schröter (4) and Hinz (10) talk about three successive acceleration phases: Acceleration of the whole thrower-javelin system using the speed and strength of the legs; Acceleration of the throwers trunk. By bracing the lower parts of the body (mass) energy is transferred to the upper parts of the body (small mass), thus causing them to accelerate; Acceleration of the thrower's arm and hand and the javelin. By bracing the upper parts of the body the energy is transferred to the lower arm, hand and the javelin. This leads to a further increase of velocity.

For javelin throwing, the high speed of the movement in the release phase causes problems for athletes, coaches, and researchers because feedback on movement performance is hardly available. Usually the athlete receives only feedback in form of throwing distance. Since e.g. indoors the necessary area is not always available for appropriate throwing distance, alternatives for this special purpose must be developed.

During the bracing stride, the throwing arm should be still extended in a relaxed way and aligned horizontally. This is important because allowing the throwing arm to drop will make it exceedingly difficult, if not impossible, to achieve the required bow tension of the whole body. The extended posture of the arm is justified by the advice to make the final acceleration path as long as possible. This creates maximum v0, when v0 correlates with throwing distance (0.92) that is considered by Bartonietz (3) that throwing distance is influenced by the following main variables:

1) Velocity of release

2) Angle of release

3) Angle of attack

4) Height of release

The achieved result of the throw depends on Physical variables, motor abilities, and throwing technique (2).

In Tutjowitsch's opinion (25) the throwing technique requires great throwing explosive strength and the ability to perform the elements in the precise moment and in limited space. The javelin thrower has to optimize the angle of release, the release velocity and the height of release so as to achieve the maximum throwing distance.
Further, the theoretical distance was calculated by the following estimate equation.

$$
D=\frac{\mathrm{V}_{0}{ }^{2}}{\mathrm{~g}} \cos \alpha_{0}\left[\sin \alpha_{0}+\sqrt{\sin ^{2} \alpha_{0}+\frac{2 \mathrm{gh}_{0}}{\mathrm{~V}_{0}^{2}}}\right]
$$

D; the theoretical distance

$\mathrm{V} 0$; the initial velocity at the moment of javelin release

$\mathrm{g}$; the acceleration due to gravity

$\alpha 0$; the release angle

h0; the release height

The javelin throw result (D) may be physically defined by the following formula on the assumption that air resistance is disregarded (see Figure 2).

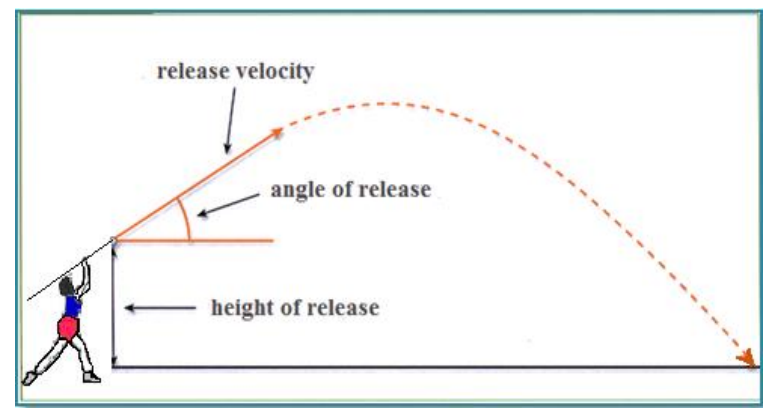

Figure 2. Trajectory of a javelin throw

Figure 2 show physical variables for the acceleration phase in the javelin throw. The best combination of throwing velocity, angle and height of ejection. The highest correlation exists between the throwing distance and release velocity. That is the most important factor in throwing. Schwuchow (21) indicates that the throwing distance influenced with many complicated mechanical variable like $\mathrm{V}_{0}$ release velocity of throwing, $\alpha_{0}$ angle of release, ho height of release.

When the main objective is to achieve more distance, the athlete should be aware of the principles of biomechanics and some important characters such as the angle and velocity of release. The studies of Hinz (10) and others show that the velocity was more influencing in throwing distance which reached $30 \mathrm{~m} / \mathrm{sec}$ for male. Such information seem to be very difficult to get and evaluate through vision of a movie analysis due to the high speed of movement, see figure 2 that shows the ideal angle of release with 38 for male athletes, according to Schwuchow (21). In recent decades, the sports 
science discipline in track and field javelin throwing is concentrated. The following summarizes the current state of knowledge of the movement structure; javelin throwing technique, physical parameters of the javelin throwing and the use of special rapid information in the context of the development and improvement of the javelin performance is presented (Figure 3 ).

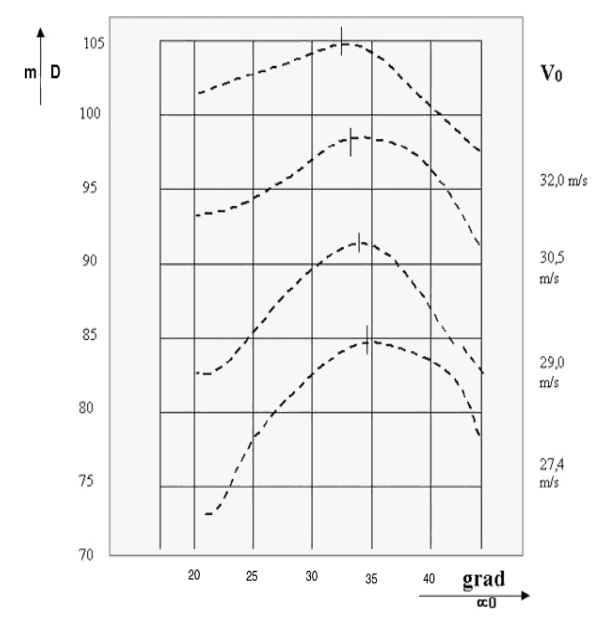

Figure 3. Relationship between D, $\alpha_{0}$ and $\mathrm{V}_{0}(21)$

\section{Sport history development of the Javelin}

With the beginning of the 20th century and its increasing organization of the sport has evolved over the decades, the javelin throw technique more and more improved. This is also good to pursue the permanent increase in javelin throw distance. The results presented in Figure3 Records in javelin throw since 1883.

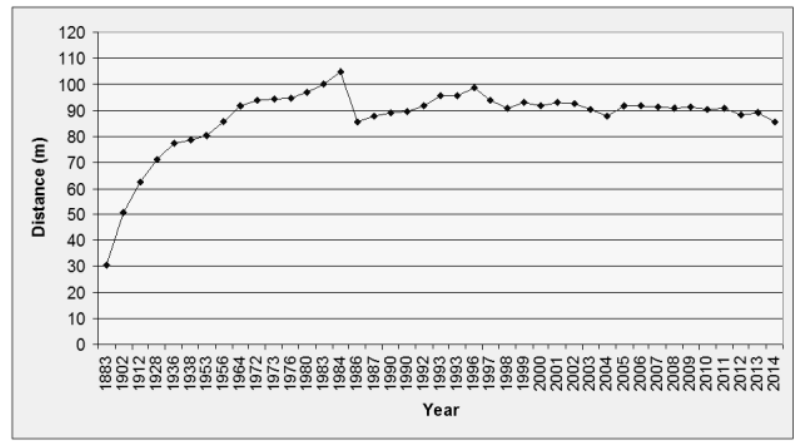

Figure 3. Diagrammatic of records in javelin throw

Not just the throwing technique, but also the material had influence on the achieved javelin performance. 1953 „Bud Held“ (USA) get the javelin (wood), Which increased the ability to fly horizontally, and paying the javelin left. In 1954, he then developed a variant of metal, which could be thrown further.

Due to the technical, material and trainingprogress, the IAAF had to make several regulations to prevent large and thus dangerous throws in athletics stadiums. With this technique, the javelin could be thrown for over $100 \mathrm{~m}$. The $100 \mathrm{~m}$ line was then crossed again in 1984, after which the IAAF setting out a new regime for the javelin Construction. "In response to this wide-open space was moved by a rule change from 01.04.1984, the focus of the javelin to $4 \mathrm{~cm}$ in front, which had reduced widths, hitting a steeper and better selection options than in the peer Sail result (14). As of 01/01/1992 it has banned any roughening of the javelin so that a smooth surface and required characteristics without any user intervention. Since 1996, the permanent improvement of the record in the javelin is stagnating. It seems as if an increase in the javelin throw performance in the context of regulations is hardly still possible.

In recent decades, the sports science discipline in track and field javelin throw on the optimization of a perfect throwing technique and their training is concentrated. The following summarizes the current state of knowledge of the movement structure, javelin throw technique, physical parameters of the javelin throw and the use of special rapid information in the context of the development and improvement of the javelin performance is presented, see Figure 4.

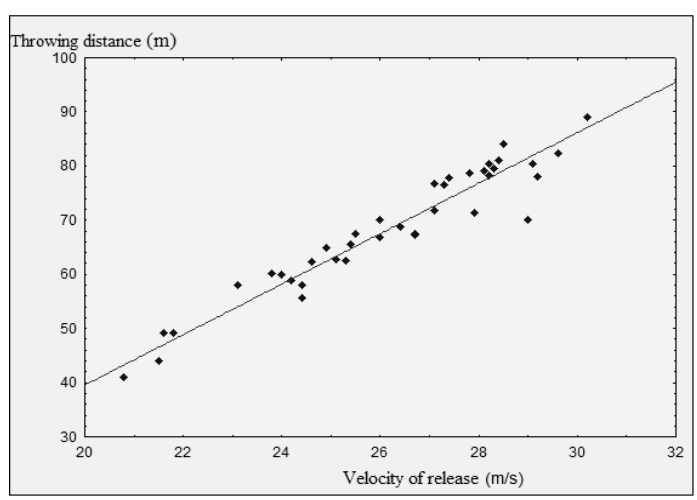

Figure 4. Relationship between D and $\mathrm{V}_{0}$

Figure 4 shows the relationship between throwing distance and the release velocity during javelin competition which reached 0.95 positive significant.

A problem in the area of the javelin throw is the high speed of movement in the ejection phase, the objective feedback from the athlete's own perception 
of movement very difficult. Usually the athlete receives the feedback about the quality of projectile motion solely on the distance thrown. As for example in warehouses not always necessary space for such throws given, it is for this specific purpose, to develop alternatives that provide at least the dominant primary determinant of throw, the departure rate information.

Teaching often assume that using immediate feedback is always a valid way to improve skill. Technologies developed to enhance performance based on such intrinsic sensory information depend on the type of skill and the learning phase (22).

Thus, it is also assumed that technologies that provide immediate feedback are beneficial for learning. However, this may not always be the case. Sometimes it may be just as effective to give feedback information after some longer delay in a more specific and limited manner. This is because an over-exposure to feedback (too much information) might interfere with performance if it is provided but not needed (18). It should also be mentioned that training in the presence of immediate feedback might create a certain dependency on external information. However, as performers progress, they should become more independent and learn to rely on internal sources of information.

The methodical approach of fast objective feedback information can be justified by the fact that self-information and subjective perceptions of the movements are consciously compared with the objective information from the outside (7).

Therefore a method of measuring velocity that does not affect performance is required. To be used in a learning/training environment the results of each trial must be available almost immediately and in a form that can be easily understood and interpreted. One of the major developments of the research is the use of laser integrated with a computer to accurately measure the athlete's velocity and provides an apparatus to aid in the analysis, teaching and coaching of javelin throw.

\section{Biomechanical simulation systems in the javelin throw}

The previous research findings were an indicator to discuss all the mechanical systems in javelin throwing events. Researchers put them in table 1 according to their manipulate date.

In the first of those studies Vitasalo (26) used light signal to measure the angle and the velocity of the attack of the javelin throw. This study is similar to Adamczewsk (1) which innovated this mechanical system in the IAT. Those throwing methods are the best methods regarding to measure the velocity and to reach the information in less than $20 \mathrm{sec}$. but the negative point is the missing accuracy of the throwing velocity measurement.

The other devices by Köllner et al. (15) which were innovated in Halle (Germany) is a training device rather than measuring device, especially when combined with 4-30 $\mathrm{kg}$ and not movable. Schmucker et al. (20) innovated another mechanical system with the javelin increased in weight about 50 $\mathrm{g}$, so most mechanical factors are not accurate. The descriptive method is the suitable way to handle such information, but this study is more advanced by using the laser light as modern and sophisticated device activities.

Table 1. Work for biomechanical simulation system in the javelin throws.

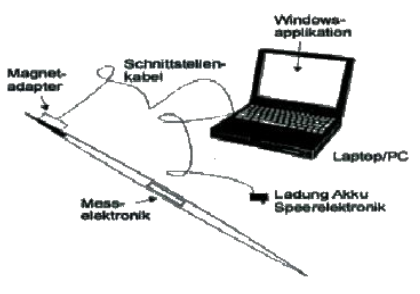

Measuring method: velocity sensor

Parameter: $\mathrm{Vo}, \mathrm{Sa}$

Author: Schmucker, U.; Warnemünde, R.; (2001)

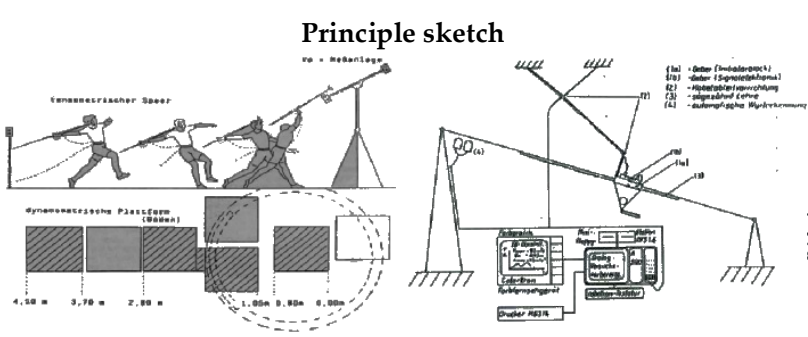

Measuring method: Light cells

Parameter: $\mathrm{Vo}, \propto 0$

Author: Adamczewski, H. (1995)

\section{Measuring method: receiver of acceleration \\ Parameter: \\ Vmax, Sa, V(t)}

Author: Köllner, J.; Dörr, J.; Wiese, G. (1989)

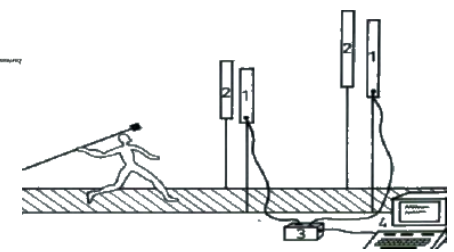

Measuring method: Light cells

Parameter:

$\mathrm{Vo}, \propto \mathrm{O}$

Author: Viitasalo, J.; Korjus, T. (1987) 
The aim of this study is a Trying to identify using a movable technological simulation system for kinematic analysis to provide immediate accurate feedback and predict javelin throw distance. According to the research objectives, the research hypothesis assembled as the following question: Could we expect the throwing distance (D) in relation to the initial velocity at the moment of javelin release $\left(\mathrm{V}_{0}\right)$ ?

\section{MATERIAL \& METHOD}

The descriptive style is the suitable one for this research and to study also the relationship between distance performance and velocity of release to predict javelin throw distance.

\section{Research Sample}

There were 20 sport student selected as randomly. Everyone has performed three throwing attempts according to the IAAF regulations on the field and other three ones on the information technological system in javelin throw. The best attempt was selected from both of them respectively. For statistical analysis the mean and standard deviation as well as Skewness for age, body mass and height (Table 2).

Table 2. Characters of the sample $(\mathrm{N}=20)$.

\begin{tabular}{lccc}
\hline Variables & Mean & Standard Deviation & Skewness \\
\hline & & & \\
Age (years) & 18 & 0.70 & 0.16 \\
Body Mass (Kilogram) & 84.4 & 7.30 & -0.02 \\
Height (Meters) & 1.74 & 5.50 & 0.26 \\
& & & \\
\hline
\end{tabular}

\section{Procedure}

Biomechanical simulation system for immediate information in the javelin throws:

Sport has become, in all sectors, closely linked to the use of technology. The use of the computer with modern instruments has now become a medium of instruction in many areas of sports, which assists in the process of assessment and forecasting directly and objectively. Learning, in recent time, became an investment process which is connected with production and economic abilities. Sport and physical education became strongly connected with technology and using computers with new measuring devices became more familiar with learning and training methods. Gesse (8) and Daugs (6) believe that information technology could help to get fast information about sport performance. Grosser \& Neumaier (9) indicate that feedback information about athlete movement were very fast (20-30s). When such fast information comes directly, it would be better to store movement information in athlete's memory.

\section{Basic Approach}

The basic idea of the simulation, the acceleration of a javelin throw javelin model is used on an inclined plane. A tube functions as a model of a spear and is located on an approximately sevenmeter-long rope. The rope is) between two fixed points at different heights tense (inclined plane. The spear model (tube) can slide freely between the two points, so that the javelin thrower this speed with the hand in the direction of the elevated point.

So that the athlete will be given the option of dropping technique of the javelin to exercise control on the model (Figure 5).

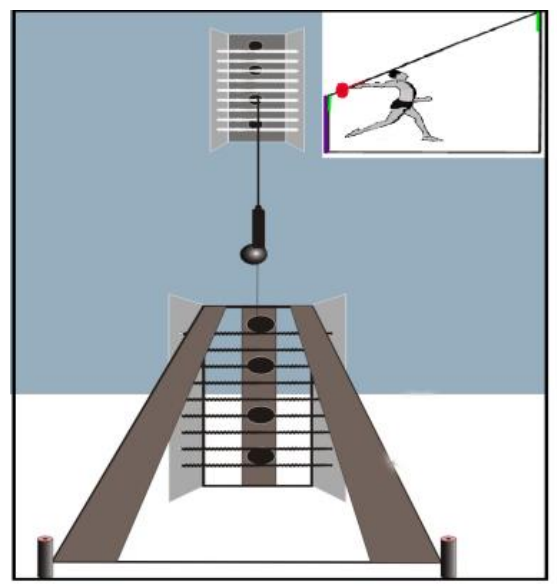

Figure 5. The technique of the javelin throw on the model.

In addition to simulating the dropping technique should be both rapid and quantitative statement about the speed of the javelin throw model possible in order to meet the demand to use the unit as rapid information to. The problem of velocity measurement is achieved using a laser measurement device (LAVEG), the distance by measuring the javelin throw model in relation to the laser facility in a position to determine the dropping during simulation, the values for these physical parameters. However, this can only be done in conjunction with an appropriate software (DAS3) and hardware (PC or laptop).

The entire system consists of 3 parts indicated:

1. Including steel rods and litter sled. 
2. LAVEG laser velocity device and special software (DAS3 - Program) for the electronic evaluation.

\section{PC or laptop}

A movable technological system for the analysis of the javelin technique was developed, which consisted of a $800 \mathrm{~g}$ sledge to be accelerated along a rope and a LAVEG measure unit. Takeoff angles can be adjusted within the range of $26-40$ degrees. The takeoff height can be likewise adapted to the individual conditions of the athlete. The LAVEG is connected to a PC or laptop using the DAS3 - program, which was also developed by the company JENOPTIK can thus very quickly about the velocity of the throw will be seen and evaluated immediately after the sled test on the screen. Due to the high relationship between release velocity and throwing range in javelin, the release velocity of the simulated javelin throw serves as indicator of the throwing performance. This information can be provided as feedback within 5 to 10 seconds on a screen (Figure 6).

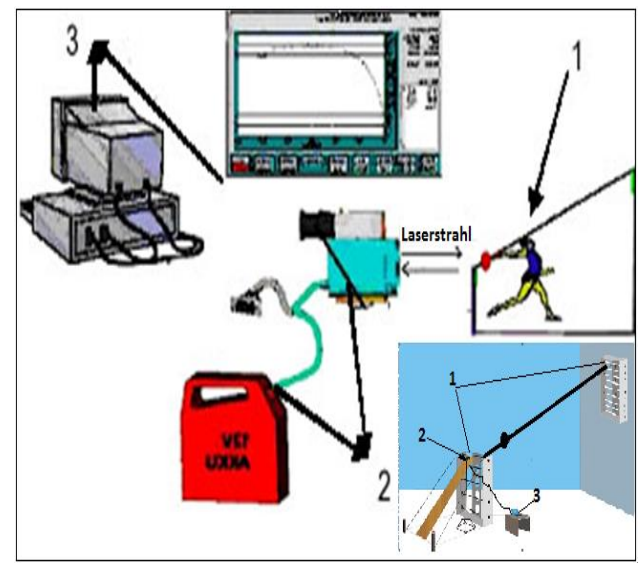

Figure 6. Schematic illustration of laser-based guidance and feedback in Javelin throw.

The newly developed laser diode system LAVEG (LASER Velocity Guard - JENOPTIK Technology GmbH, Jena) opens up new prospects of carrying out kinematic analysis of one-dimensional acceleration phases in various kinds of sports. The distance-time and velocity-time functions of interest as well as individual kinematic parameters of a motion, they are immediately available to trainer and sportsman as instantaneous information. The purpose of the present study was to verify the accuracy of this new measurement system in javelin throw.
Later in the program, there are DAS3 data on the screen numerically and graphically and presented with various additional information to determine the relationship between velocity and distance to time, and velocity to time with a diagram chart to describe this relationship on the axle $Y, X$ accordingly, it shows the connection of those parts within $10 \mathrm{sec}$. (12).

The test setup, as depicted in Figure $6 \mathrm{Nr}$. 2, shows both measurement techniques simultaneously utilized for velocity measurements. The laser beam is deflected by a reflector attached to the back of the sledge especially for this purpose, while at the same time a glow lamp (140 Hz) was mounted to the device in order to record the light pulses on a photo plate by means of a specific photogrammetric camera.

\section{Scientific Processing (Validity and Reliability) of the dynamic simulation system}

10 sample (Students) completed three test throws the movable technological simulation system with laser. The initial velocity was (after three days) at a repetition of the measurement under the same conditions and at the same objects repeated. There were almost always the same results exist. The calculation of reliability $(r=0.92$, significance $\mathrm{p} \leq$ 0.05 ) showed a high reliability of the analytical method.

Criterion is a special aspect of construct validity. This is when the measurements with another construct valid measurement of the criterion are highly correlated. The correlation coefficient indicates the strength of the relationship between the parameters of departure velocity of javelin throw $\left(V_{0}\right)$ and the parameters of the initial velocity on a movable technological simulation system with laser $\left(\mathrm{V}_{0} \mathrm{~g}\right)(\mathrm{r}=0.88$, significance $\mathrm{p} \leq 0.05)$. This means test by a movable technological simulation system with laser is valid, because it correlates with test $\mathrm{V}_{0}$.

For the statistical analyses SPSS (version 16) was used (BORTZ, 2005).

\section{RESULTS \& DISCUSSION}

With the help of linear regression, we can now directly relate to each other 2 parameters. In the subsequent regression is expected to be predicted with any other characteristic feature of $X$ and $Y$, the connection can be represented by a straight line. In addition, a precise statement for $\mathrm{Y}$ can be taken as soon as $\mathrm{X}$ is known. This means: "What is happening to $Y$ in terms of $X^{\prime \prime}(17)$. 
The coefficient correlation was 0.84 which is statistical value in indicator 0.01 . Figure 7 shows these consequences (the expectation formula for this variable) Distance of throw $=$ static factor variable $X$ S1.

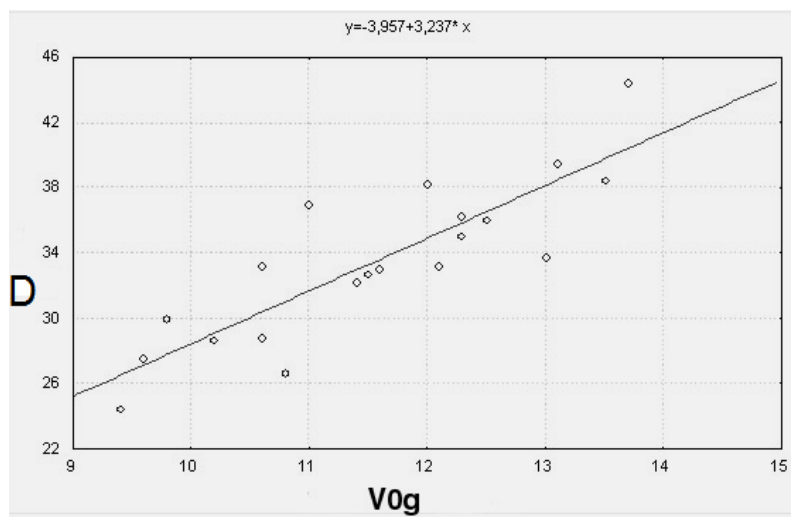

Figure 7. Representation of the connection between the parameters $\mathrm{D}$ and $\mathrm{V}_{0} \mathrm{~g}$

The Technological Movable System in the javelin throw can measure the maximum velocity, which owns the slide on the rope.

Bartonitz (3) and Tünnemann \& Freyer (24) through their research, prove that program of mechanical training have a positive influence on the physical abilities and it could use as special way to measure mechanical and physics of performance.

Results In less than 10sec we could predict of the distance performance throw expectation formula:

$$
\mathrm{D}=3,957+3.237 \times \mathrm{V}_{\mathrm{og}}
$$

Which is better than manipulating through video analysis or movie camera in addition to highly coast of training halls, trainers, training programs and other things. Also this device is movable ,easy to carry and store and do not need large space.

Any technology and device that is constructed around the idea of immediate feedback from diverse sources may be relevant for recreational, professional or amateur performers at the initial stages of the skill acquisition process. Initially, welldefined and understandable feedback will enhance learning. However, when experience is acquired, individuals are expected to rely on specific feedback from external sources and on intrinsic feedback. That is, they should become sensitive to their own mistakes in skill performance by focusing on relevant information and internal sensation.
It is important to provide accurate information about a performance to an athlete improving a skill. Delay in providing the information reduces the likelihood that the athlete will be able to make effective use of the feedback. Performance testing would be much more effective if the test was carried out in a normal training or competitive situation and if the results were available to the athlete and coach immediately after each performance.

Hodges \& Franks (11) suggest, therefore, that the frequent use of different feedback sources is important and relevant at the beginning of the skill acquisition process, but less important later, this issue for a discussion of pre-practice information provided early in learning.

The results, which the coaches immediately after the test are available, this can have a positive impact on the performance of athletes wide. Here, the use of quick information when measuring training so far proved to be particularly successful, as reflected in various scientific works Köllner (15) and Daugs (6) confirmed is. This is the Quickunderstand after Thorhauer (23), as an "objective" additional information that can be obtained by using technical measuring equipment.

The information would also help sport scientists and coaches gain a better understanding of javelin throw. To provide these information competitive starting blocks that provide reliable and valid force data and a method of measuring velocity that does not affect performance is required. To be used in a learning/training environment the results of each trial must be available almost immediately and in a form that can be easily understood and interpreted.

In fact, at advanced stages, elaborate 'summary feedback' might incorporate combined information from all feedback channels and have positive effects on performance $(19,27)$. In light of the rather general character of technologies often built to train individuals, it is unlikely that they can adjust to meet a specific need for a feedback source. Hence, coaches should be aware of the differential needs of their athletes at the different stages of the learning process.

In conclusions, teachers and coaches strive constantly to improve the performance of athletes. The most important aspect of their role is to provide the athlete with a practice environment that is conducive to effective and efficient learning. The introduction of information technology into the 
sport performance environment appears to be a positive, although not always essential, step towards achieving this goal. When the athlete can compare internally the expected optimum performance with the actual movement outcome, the probability of learning increases. This review has focused on how information technology has been used to provide the athlete and coach with sophisticated, objective information about sport performance.

The LAVEG laser diode system provides substantially enlarged possibilities for motion analysis during sports events. While allowing a more differentiated approach to all types of movement which may be an integral part of any program. Learning and Training support can thus be claimed as one of the key benefits offered by LAVEG. This measurement system featuring the following aspects:
1) Instantaneous training-supporting information available at the training site
2) Uncomplicated technical handling of the measurement device

\section{Suggestions:}

1) Using this new simulation system to predict the distance performance and evaluate physical variables in Javelin throwers.

2) Test and evaluate learning and training programs

3) Using this system to test some mechanical variables in sport events especially those which are from repeated movement type.

\section{REFERENCES}

1. Adamczewski H. Untersuchungsergebnisse vom Messplatz Speerwurf. Die Lehre der Leichtathletik, 1995; 17: 97-100.

2. Ballreich R, Kuhlow A. (1986): Biomechanik des Kugelstoss, In: Ballreich, A, Bionnechanik der Sportarten, Ferdinand Enke Verlag, Stottgart, 1986; 89-109.

3. Bartonietz K. Zur Sportlichen Technik der Wettkampfübungen und zur Wirkungsrichtung Ausgewählter Trainingsübungen in den Wurf- und Stoßdisziplinen der Leichtathletik. Leipzig: Univ., Diss, 1987; 23,57 .

4. Bauersfeld KH, Schröter G. Grundlagen der Leichtathletik, 5. Aufl., Sport und Gesundheit verlag, Berlin, 1998; 299.

5. Bortz J. Statistik für Sozialwissenschaftler, 6 Aufl., Springer Verlag, Berlin, 2005.

6. Daugs R. Evaluation sportmotorischen Messplatztrainings im Spitzensport, 1. Aufl., Sport und Buch strauß, Köln, 2000; 38.

7. Farfel VS. Bewegungssteuerung im Sport, Berlin, 1977.
8. Geese R. Technisch- apparative Möglichkeiten zur Leistungsdiagnostik und -steuerung mittels objektiver Schnellinformation, Leistungssport, Nr. 2, 1992; 31-33.

9. Grosser M, Neumaier A. Techniktraining, Theorie und Praxis aller Sportarten, BLV Verlagsgesellschaft, München, 1982; 81, 84 .

10. Hinz L. Leichtathletik, Wurf und Stoss, 1. Aufl., Sportverlag, Berlin, 1991; 15-18, 20.

11. Hodges NJ, Franks IM. Modelling coaching practice: the role of instruction and demonstration. Journal of Sports Sciences, 2002; 20: 793-811.

12. Jenoptik. Laser, Optik, Systeme GmbH, Distanz-Auswertung 'SPORT', Programm- Beschreibung Version 3.7, Jena, 2000.

13. Joch W. Rahmentrainingsplan für das Aufbautraining, Wurf, 2. Auflage, Meyer \& Meyer Verlag, Aachen, 1993; 172.

14. Jonath U, Krempel R, Haag E, Müller H. Leichtathletik 3, Werfen und Mehrkampf, Rowohlt Verlag, Hamburg, 1995; $132,157$.

15. Köllner J, Dörr J, Wiese G. Der Einsatz von Mess- und Bürocomputertechnik am Krafttrainingsgerät Speerwurf zur Bereitstellung von Sofortinformationen im Training, Theorie und Praxi Leistungssport, Nr. 2, 1989; 54-63.

16. Morriss CJ, Bartlett RM. Biomechanical factors critical for performance in the javelin throw. In: Sports Medicine 1996; 21(6): 438-446.

17. Rohland U. Statistik, Erläuterung grundlegender Begriffe und Verfahren, Shaker Verlag, Aachen, 2000; 48.

18. Salmoni A, Schmidt RA, Walter CB. Knowledge of results and motor learning: a review and critical reappraisal. Psychological Bulletin, 1984; 95: 355- 386.

19. Schmidt RA, Lange C, Young DE. Optimizing summary knowledge of results for skill learning. Human Movement Science, 1990; 9: 325- 348.

20. Schmucker U, Warnemünde R, Ritschel M. Digitaler Wurfspeer- Beschleunigungs- und Geschwindigkeitsmessung im Leistungssport, Leistungssport, Nr. 5, 2001; 32-34.

21. Schwuchow H. Anforderungen an die Charakteristik des finalen Krafteinsatzes zum Erreichen der Prognoseleistungen im Speerwurf, Diplomarbeit, Leipzig Univ., 1986; 11,12.

22. Shea $\mathrm{CH}$, Wulf $\mathrm{G}$. Enhancing motor learning through external-focus instructions and feedback. Human Movement Science, 1999; 18: 553- 571.

23. Thorhauer HA. Zur Zeitstruktur der „objektiven ergänzenden Schnell- Information" Theorie und Praxis der Körperkultur, $1971 ; 390$.

24. Tünnemann $H$, Freyer K. Diagnostik und Training technikorientierter Kraftfähigkeiten mittels ringkampfspezifischer Bewegungssimulatoren, Institut für Angewandte Trainingswissenschaft (Hrsg.), Meyer \& Meyer Verlag, Leipzig, Nr. 3, 1995; 105-121.

25. Tutjowitsch VN. Theorie der sportlichen Würfe, Teil 1, Informationen zum Training, Beiheft zu Leistungssport, 1969; $3,9 f$.

26. Viitasalo J, Korjus T. Messung der Abwurfgeschwindigkeit und des Abwurfwinkels beim Speerwurf, Leistungssport, Nr. 4, 1987; 39-41. 
27. Winstein CJ, Schmidt RA. Reduced frequency of knowledge of results enhances motor skill learning. Journal of Experimental Psychology: Learning, Memory and Cognition, 1990; 16: 677-691. 